\title{
Dr. J osé López Sánchez (1911-2004): en el centenario de su nacimiento
}

\author{
Dr J osé López Sánchez (1911-2004) in his $100^{\text {th }}$ birthday
}

\section{Dr. Gregorio Delgado García}

Ministerio de Salud Pública. La Habana, Cuba.

\section{NTRODUCCI ÓN}

El 4 de junio del presente año se cumple el centenario del nacimiento del doctor J osé López Sánchez (1911-2004), quien junto a los doctores Rafael A. Cowley Valdés-Machado (1837-1908), José A. Martínez-Fortún Foyo (1882-1960) y el académico César Rodríguez Expósito (1904-1972), constituyen las cuatro máximas figuras de la historiografía médica cubana.

Por tal motivo no era posible dejar de conmemorar aniversario de tal importancia, responsabilidad que asumen la Sociedad Cubana de Historia de la Medicina, de la que fue miembro fundador y Presidente de Honor; la Sociedad Cubana de Salud Pública y la Oficina del Historiador del Ministerio de la Salud Pública, las que delegan en mí la difícil tarea de pronunciar su panegírico, quizás porque fuera su alumno en las aulas universitarias y ser el más rendido admirador de su obra científica.

\section{NACI MI ENTO Y ESTUDI OS}

El doctor José López Sánchez nació en la ciudad de La Habana el 4 de junio de 1911, hijo de José López Buribela, electricista español, que supo inculcar en su descendiente, desde muy joven, las inquietudes sociales que lo acompañaron toda su vida y de su esposa I rene Teresa Sánchez Almeida (Certificado de nacimiento. En: Universidad de La Habana. Archivo Histórico. Exped. Est. 17246). 
Trasladada la familia, sucesivamente, para las ciudades de Santiago de Cuba y Santa Clara, en colegios de ambas cursa la instrucción primaria y en el Instituto de Segunda Enseñanza de Santa Clara se gradúa de Bachiller en Letras y Ciencias (1928) y allí tiene como profesor al doctor Joaquín Tristá Pérez, médico villaclareño de sólida cultura científica y humanista, graduado en París, quien va a influir culturalmente en su inquieto e inteligente alumno. ${ }^{1}$ En eL propio año de su graduación inicia sus estudios superiores en la Facultad de Medicina de la Universidad de La Habana, donde se acababa de poner en vigor un nuevo plan académico, que constaba de un año de premédica y seis años de estudios propios de la carrera. El estudiante López Sánchez aprueba el año de premédica y comienza el primero de medicina en el curso 1929-1930 y al terminarlo es clausurada la Universidad por la dictadura del general Gerardo Machado Morales (1925-1933) y quedan interrumpidos sus estudios por tres largos años.

La caída de la dictadura el 12 de agosto de 1933, abre nuevamente las puertas de la Universidad y el estudiante López Sánchez continúa la carrera y labora como alumno del Hospital Municipal de Emergencias "General Fernando Freyre de Andrade", donde gana 20 pesos mensuales.

La Universidad se cierra de nuevo en 1935 y se abre para el curso 1936-1937. En septiembre de este último año marcha a España en plena sangrienta guerra civil al Congreso Mundial de Estudiantes Antifascistas y permanece en ella como corresponsal de guerra hasta enero de 1938. De regreso a Cuba aprueba con altas calificaciones las asignaturas que le faltan para graduarse de Doctor en Medicina en julio de 1938.

Realizó los ejercicios de grado en las salas "Torralbas" y "Gordon" de nuestro querido Hospital Universitario "General Calixto García", ante un tribunal de examen presidido por el doctor Alfredo Antonetti Vivar (1890- ?), profesor titular de Enfermedades Tuberculosas con su Clínica, el que le otorgó la calificación de Sobresaliente (Universidad de La Habana. Archivo Histórico. Exped. Est. 17246).

El doctor López Sánchez tuvo tiempo, también, a pesar de su intensa actividad política, de la que después hablaré, para especializarse en dermatología durante varios años junto al profesor titular doctor Braulio Sáenz Ricard en su cátedra de Enfermedades de la Piel y Sífilis de la Facultad de Medicina, sala "Raimundo Menocal" de nuestro igualmente querido y siempre recordado Hospital Universitario "Nuestra Señora de las Mercedes" y hasta el triunfo de la Revolución ejerció como dermatólogo del Centro Benéfico Jurídico de Trabajadores de Cuba (1943-1962), institución mutualista de atención médica secundaria sufragada por el partido Socialista Popular. ${ }^{2}$

\section{ACTI VI DADES REVOLUCI ONARI AS Y POLÍTI CAS}

Desde su ingreso en el alto centro docente habanero se incorpora el joven de 17 años de edad José López Sánchez a sus luchas estudiantiles, en las que ya participaba desde 1925 en la segunda enseñanza y su actividad revolucionaria se intensifica con la clausura de la institución, lo que lo lleva en 1932, con 21 años de edad, a militar en el Partido Comunista de Cuba, entonces en la clandestinidad desde su fundación en 1925.

En él colabora, entre otros, con el doctor Federico Sotolongo Guerra (1905-1997), primer médico que militó en dicho Partido, lo que hizo desde 1929. El doctor Sotolongo que llegó a ser un eminente profesor de la cátedra de Parasitología y 
Enfermedades Tropicales, en aquellos momentos era instructor en la de Clínica Médica, ambas de la Facultad de Medicina de la Universidad de La Habana. ${ }^{3}$

A la caída de la dictadura, el Partido Comunista no logra su legalización, pero se funda una organización política de fachada, el Partido Unión Revolucionaria, donde va a militar el connotado médico y revolucionario marxista, doctor Gustavo Aldereguía Lima (1895-1970) y algunos estudiantes de medicina, como el después eminente psiquiatra doctor José A. Bustamante y O'Leary (1911-1987). López Sánchez colabora con el doctor Aldereguía, pero sigue militando en el clandestino Partido Comunista.

En 1938 dicha institución política se legaliza y se une al Partido Unión Revolucionaria para formar el Partido Unión Revolucionaria Comunista, en el que va a continuar el doctor López Sánchez su activa militancia y cuando este cambia su nombre por el de Partido Socialista Popular, en él se prolonga su incansable e inclaudicable militancia.

Pero donde va a ser más efectiva su labor política, es en las luchas del gremio médico por alcanzar sus justas mejoras laborales, a las que se incorpora desde su graduación en 1938, primero en la Federación Médica de Cuba y a partir de 1944 en el Colegio Médico Nacional, organizaciones gremiales en las que desempeña importantes cargos. Algún día tendremos que destacar con mayor amplitud este notable quehacer. ${ }^{1}$

\section{LABOR DOCENTE}

Por los años de las décadas de 1940 y 1950 imparte, por primera vez en Cuba, cursos de Medicina Industrial en la Escuela de Verano de la Universidad de La Habana.

Años mas tarde integra el grupo de los que llevan a cabo la gran reforma universitaria de 1962, que dará a Cuba los planes de estudios para la formación del profesional idóneo para la nueva sociedad socialista cubana y abre nuevamente en la Facultad de Ciencias Médicas de la Universidad de La Habana la cátedra de Historia de la Medicina, suprimida desde 1899, que desempeña durante seis años y para la que escribe, muy rápidamente, su libro de texto "Curso de Historia de la Medicina (Desde los tiempos primitivos hasta el Renacimiento)" (1961), en un tomo. ${ }^{4}$

De esta obra vieron la luz dos ediciones, una para los estudiantes, sin ilustraciones y otra menos numerosa, con mejor impresión y 81 ilustraciones. Unos años mas tarde apareció una tercera edición ilustrada para estudiantes, pero sin fecha, sin pie de imprenta, ni el nombre del autor.

La obra presenta una evidente influencia de Henry E. Sigerist (1891-1957), lo que fue apuntado sobre todo en el extranjero, pero el doctor López Sánchez no trató con ella de hacer obra original, sino llenar un vacío lo más rápidamente posible y lo logró ampliamente.

Al final de su vida le era recompensada esta notable, aunque breve labor en la enseñanza universitaria, al otorgársele el grado docente especial de Profesor de Mérito del Instituto Superior de Ciencias Médicas de La Habana, en acto solemne, el 4 de junio de $2004 .^{2}$ 


\section{OBRA HI STORI OGRÁFI CA}

Desde sus días de estudiante en la Facultad de Medicina de la Universidad de La Habana, su sensibilidad por la cultura en todas sus manifestaciones lo hizo ser un voraz lector y a pesar de estar suprimida la asignatura de Historia de la Medicina en nuestros planes de estudio, se convirtió en un sistemático estudioso de tan importante rama del conocimiento médico, principalmente en obras como "Historia de la Medicina. Desde su origen hasta el siglo XIX" (1871) de Paul V. Renouard, muy conocida en Cuba; "Introducción a la Historia de la Medicina" (1921), dos tomos, de Fielding H. Garrison e "Historia de la Medicina" (1941) de Arturo Castiglioni, hasta llegar a descubrir la maravillosa obra en general de Henry E. Sigerist, el más importante historiador médico de todos los tiempos, pero principalmente su imprescindible obra "A History of Medicine" (1951), primer tomo.

Con esta formación autodidacta, pero muy sólida, es que comienza el doctor López Sánchez en los años de la década del 1940, su extraordinaria labor en el campo de la investigación de la historia médica cubana, a la cual me referiré con la cita y algunos comentarios de sus principales obras.

No es posible conocer la historia de la medicina en Cuba sino estudiamos los orígenes de su desarrollo, a punto de partida de la misma como práctica social; de su organización en función de la sociedad y de los inicios del pensamiento científico capaz de dar respuesta a los problemas médicos nacionales.

Y no pudo escoger mejor el doctor López Sánchez el personaje para sus primeros estudios. Tomás Romay Chacón (1764-1849), a pesar de su evidente papel protagónico en los momentos del despertar de la conciencia nacional, no estaba correctamente valorado por nuestros historiadores clásicos. El doctor López Sánchez estudió la totalidad de los escritos de Romay y todo lo que se había publicado sobre él y así nos va a dar un primer libro sumamente valioso, "Tomás Romay. Apuntes biográficos y discursos" (1950), volumen de 317 páginas, que apareció como Número 6 , Octava Serie, de Cuadernos de Cultura. ${ }^{5}$

Precedido de un esclarecedor prólogo, el libro se inicia con un artículo biográfico sobre Romay de Anselmo Suárez y Romero (1818-1882) y se cierra con el Elogio escrito a su muerte por Manuel Costales Govantes (1815-1866). Comprende, además, cuatro trabajos de Romay y un estudio de López Sánchez de un valor documental extraordinario. Con el título "Tomás Romay en la Sociedad Económica", nos ofrece un verdadero libro pues consta de 140 páginas, en las que comenta y transcribe la documentación del sabio médico en tan importante institución.

Ese mismo año en la Editorial y Librería "Selecta" de La Habana ve la luz su libro mayor "Vida y obra del sabio médico habanero Dr. Tomás Romay Chacón. 1764$1849 ", 6$ volumen de 420 páginas donde expone una esclarecedora biografía sobre Romay, en que lo sitúa definitivamente en el lugar histórico que le corresponde, junto a Francisco Arango y Parreño (1765-1837) y J osé A. Caballero Rodríguez de la Barrera (1771-1835).

Esta obra mereció los premios "Francisco González del Valle", de la Sociedad de Estudios Históricos e Internacionales y el de la Federación Médica de Cuba, así como el elogio unánime de historiadores y de la crítica nacional. 
Tres lustros después con motivo de celebrarse el bicentenario del nacimiento del sabio, escribió una nueva versión con el título "Tomás Romay y el origen de la ciencia en Cuba" (1964), ${ }^{7}$ volumen de 302 páginas, con prólogo del notable historiador doctor J ulio Le Riverand Brussone (1912- ?), que fue traducido al inglés, francés y al ruso.

Pero no satisfecho con este aporte, lo completó definitivamente con la recopilación de todos los trabajos y documentos del fundador del movimiento científico en Cuba y los publicó en "Tomás Romay. Obras Completas" (1965), ${ }^{8}$ dos tomos, que comprenden 688 páginas y un tercero, que apareció en 1972, con los índices de nombres, de materias y geográfico.

Con el título de "La Medicina en La Habana. 1550-1799 (Cronología de los hechos médicos consignados en las Actas Capitulares del Ayuntamiento de La Habana)" (1970), 9,10 dos volúmenes de 318 y 313 páginas cada uno, recopiló y trascribió 530 documentos extraídos de 50 libros con actas capitulares, de 57 con actas trasuntadas y de 3 con actas impresas. La obra es imprescindible para el conocimiento documental de la historia de la medicina en Cuba, anterior a la aparición de la prensa médica.

En el tomo I de "Carlos J. Finlay. Obras Completas" (1965), ${ }^{11}$ recopiladas y publicadas por el académico César Rodríguez Expósito, el doctor López Sánchez escribió un amplio prólogo en el que expuso ideas originales sobre la interpretación del descubrimiento de la teoría metaxénica del contagio de enfermedades infecciosas del doctor Finlay, que lo estimularon a seguir profundizando en la vida y obra del sabio, a pesar de ser de la opinión de que en los estudios biográficos publicados por J uan Guiteras Gener (1852-1925), Francisco Domínguez Roldán (1864-1942), Carlos E. Finlay Shine (1868-1944) y César Rodríguez Expósito, estaba dicho todo sobre el sabio cubano.

Este nuevo empeño investigativo del doctor López Sánchez dio como resultado una erudita y muy bien escrita biografía sobre Finlay, que aunque no alcanza la trascendencia histórica de la de Tomás Romay, si es un aporte considerable a la interpretación del pensamiento del más eminente científico cubano de todos los tiempos y uno de los inmortales de la humanidad.

Con el título "Finlay, el hombre y la verdad científica" (1987), ${ }^{12}$ volumen de 579 páginas, nos da una versión acabada de las ideas del sabio a través de su época y de las circunstancias históricas que vivió. En una segunda edición traducida al inglés con el título "Carlos J. Finlay his life and his work" (1999), ${ }^{13}$ no se circunscribe a la traducción de la anterior edición, sino que modifica en diferentes aspectos su visión original.

Pero había una gran parte de la obra del doctor López Sánchez que se encontraba dispersa en numerosas publicaciones, lo que con muy buen acierto quiso dejarnos en una valiosa recopilación que publicó en 1986 en dos tomos, con el título "Ciencia y Medicina. Historia de la Medicina". ${ }^{14}$

En el primer tomo incluyó ensayos tan valiosos como: "Un nuevo enfoque de la historia de la medicina", "Historia de las ideas médicas sobre la concepción unicista del ser humano", "Las primeras publicaciones científicas en Cuba" y "La enseñanza de la medicina en Cuba, su pasado y su estado actual. Perspectivas de su futuro desarrollo" y junto a estos, otros no menos valiosos sobre: Diego Vázquez de Hinostrosa de Artes (1626- ?), el primer cubano graduado de médico; Tomás Romay Chacón; Carlos J. Finlay Barrés (1833-1915); Claude Bernard (1813-1878); J ohn Locke (1632-1704); Henry E. Sigerist; Daniel Alcides Carrión García (1857-1885); 
J osé Elías Borges Carreras (1905-1934); Luis Díaz Soto (1905-1958) y Gustavo Aldereguía Lima (1895-1970).

En el segundo tomo nos demuestra lo enciclopédico de sus conocimientos, con profundos ensayos de historia de las ciencias en general, sobre obras de Nicolás Copérnico (1473-1543), Gregorio Mendel (1822-1884), Charles Darwin (1809-1882), Ramón de la Sagra Peris (1798-1871), Alexander von Humboldt (1769-1859), Aimé Goujaud conocido por Bonpland (1773-1858), Felipe Poey Aloy (1799-1891) y Leonardo da Vinci (1452-1519).

La última de sus obras que citaré es "Cuba. Medicina y Civilización. Siglos XVII y XVIII" (1997), ${ }^{15}$ volumen de 373 páginas, que reúne ocho importantes y eruditos ensayos, entre ellos: "Colonización española y exterminio aborigen", "Fiebre amarilla: la primera gran epidemia de 1649" y "La sífilis venérea no procedía de América; La leyenda de su origen", pero sobre todo incluye 158 minibiografías de médicos cubanos y extranjeros en Cuba, de los siglos XVI al XVIII, con bibliografía activa y pasiva de cada uno de ellos y con datos, en su mayoría, completamente inéditos y termina el volumen con una bibliografía que incluye 1270 fichas, lo que le da un valor inestimable a la obra. Es bueno decir que la misma mereció el Premio de la Crítica (1997).

Con este ligero recorrido por lo mejor de la obra historiográfica del doctor López Sánchez, he querido destacar la calidad extraordinaria que la misma encierra y que es de vital importancia su conocimiento profundo para todo aquel que se adentre en el conocimiento de la historia de las ciencias en general en Cuba y en particular de la historia de nuestra medicina.

\section{OTROS CARGOS Y RECONOCI MI ENTOS}

Cuando el Ministerio de Salubridad y Asistencia Hospitalaria se transforma en Ministerio de Salud Pública y comienza la integración del primer Sistema Nacional de Salud Único, en América, el doctor López Sánchez es el primer presidente del Consejo Científico (1961) con categoría de Subsecretario equivalente hoy a Viceministro y desde este cargo, cuando el bloqueo económico de Estados Unidos de Norteamérica comenzaba a hacerse sentir sobre nuestro país, viaja con una comisión presidida por el entonces Ministro de Salud Pública doctor José R. Machado Ventura, a todos los países del campo socialista y la India y su actuación es destacada en el establecimiento de las primeras relaciones de colaboración con dichos países en la esfera de la salud pública.

Forma parte del grupo de científicos que al cumplir la antigua Academia de Ciencias Médicas, Físicas y Naturales de La Habana su centenario, la transforma en una moderna Academia de Ciencias de Cuba; integra su Comisión Nacional organizadora y ocupa los cargos de Vicepresidente (1963) y Secretario Científico (1964). Funda, además, con el académico César Rodríguez Expósito, primer historiador del Ministerio de Salud Pública, el Museo de Historia de las Ciencias "Carlos J. Finlay" (1962), lo dirige y edita la revista "Finlay", órgano publicitario de dicha institución.

En pleno desarrollo de tan importantes tareas, la dirección nacional de la Revolución le va a encargar una delicada misión, que al parecer estaba muy alejada de su formación científica, pero no de su profunda cultura política, se le nombra Embajador Extraordinario y Plenipotenciario en la India, Bangladesh, Nepal, Bután y Afganistán (1974-1981). 
Su desempeño en general estuvo a la altura de la confianza depositada en él, pero principalmente sus informes sobre el inicio y evolución del movimiento revolucionario en Afganistán y su proyección socialista, de tan trágico final para la historia contemporánea de la humanidad. Años más tarde pasará con igual cargo a la Embajada de Cuba en Suiza (1984-1988). De regreso a Cuba, después de cumplir tan importantes misiones diplomáticas se mantendrá como asesor del Ministerio de Relaciones Exteriores hasta su fallecimiento.

El doctor López Sánchez perteneció a numerosas instituciones científicas nacionales y extranjeras y participó en no pocos congresos nacionales e internacionales sobre dermatología e historia de la medicina. Fue Especialista de Segundo Grado (Superior) en Dermatología, Doctor en Ciencias Médicas, Investigador de Mérito, Académico de Mérito de la Academia de Ciencias de Cuba, presidente de la Cátedra Especial "Dr. Gustavo Aldereguía" de la Universidad de La Habana y recibió diversas condecoraciones y distinciones.

Falleció en La Habana, mientras continuaba sus investigaciones histórico-médicas, el 9 de septiembre de $2004 .^{2}$

\section{CONSI DERACI ONES FI NALES}

Por su obra total, no hay la menor duda en calificar al doctor J osé López Sánchez como el más completo historiador médico cubano de todos los tiempos y es un deber para nosotros luchar porque algún día se puedan recopilar los trabajos que aún están dispersos y así contar con sus "Obras Completas", publicadas por la nueva Academia de Ciencias de Cuba, de la que él fue uno de sus iniciadores y poder mostrarlas a las nuevas generaciones de científicos cubanos como un verdadero patrimonio de la cultura nacional.

\section{REFERENCI AS BI BLI OGRÁFICAS}

1. Doctor José López Sánchez. En: López Sánchez J. Cuba. Medicina y Civilización. Siglos XVII y XVIII. La Habana: Editorial Científico-Técnica; 1997. p. 1-2.

2. Delgado García G. López Sánchez, José (1911-2004). En: Diccionario Biográfico Médico Hispanoamericano. Caracas: Editorial ARTEPROCA; 2007. p. 543.

3. Delgado García G. Palabras de despedida de duelo en el sepelio del doctor José López Sánchez. Cementerio "Cristóbal Colón". La Habana. Septiembre 9 de 2004 (Original en Archivo de la Oficina del Historiador del MINSAP).

4. López Sánchez ]. Curso de Historia de la Medicina. Vol 1. [Desde los Tiempos Primitivos hasta el Renacimiento]. La Habana: Imp. "Modelo"; 1961.

5. Tomás Romay. Apuntes biográficos y discursos. Recopilación y prólogo de J osé López Sánchez. Cuadernos de Cultura. Octava Serie. No. 6. La Habana: Imp. P. Fernández y Cía.; 1950.

6. López Sánchez J. Vida y obra del sabio médico habanero Dr. Tomás Romay Chacón. 1764-1849. La Habana: Ed. Libr. "Selecta"; 1950. 
7. López Sánchez J. Tomás Romay y el origen de la ciencia en Cuba (Edición en homenaje al bicentenario de Tomás Romay). La Habana: Emp. Cons. "Artes Gráficas"; 1964.

8. Tomás Romay. Obras Completas. Recopiladas por José López Sánchez. 2 tomos. La Habana: Emp. Cons. "Artes Gráficas"; 1965.

9. López Sánchez J. La Medicina en La Habana. 1550-1730. (Cronología de los hechos médicos consignados en las Actas Capitulares del Ayuntamiento de La Habana). 1ra Parte. Cuad Hist Salud Pública No. 47 [Internet]. La Habana: Inst. Libro; 1970 [citado 29 Abr 2012]. Disponible en:

http://bvs.sld.cu/revistas/his/vol_1_95/his00195.htm

10. López Sánchez J. La Medicina en La Habana. 1731-1799 (Cronología de los hechos médicos consignados en las Actas Capitulares del Ayuntamiento de La Habana). 2da Parte. Cuad. Hist. Salud Pública No. 48 [Internet]. La Habana: Inst. Libro; 1970 [citado 29 Abr 2012]. Disponible en:

http://bvs.sld.cu/revistas/his/vol_1_95/his00195.htm

11. López Sánchez J. Prólogo. En: Rodríguez Expósito C, compilador. Carlos J. Finlay. Obras Completas. TI. La Habana: Emp. Cons. "Artes Gráficas"; 1965. p. VII-XVIII.

12. López Sánchez J. Finlay el hombre y la verdad científica. La Habana: Editorial Científico-Técnica; 1987.

13. López Sánchez J. Carlos J. Finlay. His life and his work. La Habana: Editorial José Martí; 1999.

14. López Sánchez J. Ciencias y Medicina. Historia de la Medicina. 2 tomos. La Habana: Editorial Científico-Técnica; 1986.

15. López Sánchez J. Cuba. Medicina y Civilización. Siglos XVII y XVIII. La Habana: Editorial Científico-Técnica; 1997.

Recibido: 30 de mayo de 2011.

Aprobado: 20 de octubre de 2011.

Gregorio Delgado García. Historiador Médico del Ministerio de Salud Pública.

Presidente de la Sociedad Cubana de Historia de la Medicina. Ministerio de Salud Pública. Calle 23 No. 201. El Vedado 10400, Plaza de la Revolución. La Habana, Cuba. 